households. From the nutritional aspect these families are of high importance, because they contained about a quarter of the children in all households surveyed. The annual average calcium intakes for these families can be obtained with a standard error of $0.8 \%$ so that differences between two sample annual averages must be just over $2 \%$ to achieve statistical significance at the $5 \%$ level. It follows therefore that the present sample sizes may be considered just adequate to detect long-term trends in the diet of this important section of the population. Fortunately any more or less constant bias (e.g. errors in nutrient conversion factors) has little effect on comparisons over time.

\title{
REFERENCES
}

Corlett, T. (1952). Appl. Statist. т, 34.

Gray, P. G., Corlett, T. \& Frankland, P. (1950). The Register of Electors as a Sampling Frame. London: The Social Survey.

Ministry of Food: National Food Survey Committee (1952). Domestic Food Consumption and Expenditure, 1950. London: H.M. Stationery Office.

Ministry of Food: National Food Survey Committee (1953). Domestic Food Consumption and Expenditure, 1951. London: H.M. Stationery Office.

Ministry of Food: National Food Survey Committee (1954). Domestic Food Consumption and Expenditure, 1952. London: H.M. Stationery Office.

Registrar-General (1952), Census 1951 Gt. Britain: One Per-Cent Sample Tables. London: H.M. Stationery Office.

\section{Economics, Nutrition and Family Budgets}

\section{By J. A. C. Brown, Department of Applied Economics, University of Cambridge}

\section{The general problem of analysis}

I wish in this paper to consider the proper contribution of the economist to the analysis of the data collected in family food budgets, in particular of the data of the National Food Survey (e.g. Ministry of Food: National Food Survey Committee, 1953). An enterprise of the scope and magnitude of the Survey certainly requires above all things the co-operation of many disciplines; and this co-operation must, if it is to be successful, begin long before there are any results to analyse. The problems that arise in the earlier stages of planning and execution, however, will be considered outside the scope of the present paper; and I shall assume that, as is indeed the case with the National Food Survey, a team of people, including nutritional scientists, economists, statisticians and administrators, is faced with a continuous flow of data from representative samples of households. That a considerable use of theoretical concepts is needed in the analysis of such data is apparent from considerations of magnitude alone. In one year's sampling it has been customary to obtain something of the order of 7000 household budgets, and about 300 primary measurements are contained in each budget. For this vast quantity of information to be comprehended most of these measurements must be consolidated 
into a relatively small number of average measures or statistics which must be skilfully chosen to bring out what are thought to be the data's most significant features. The primary role in deciding the strategy of this selection must be played by the administrator, whose task it is to decide the relevant problems of policy which require illumination; next the nutritionist will decide the most significant measures of the diet and establish normative standards for making his judgements and recommendations; the economist, from his knowledge of market behaviour, will then consider the most important influences governing the choice of diets by individual households and set up a conceptual framework within which these influences may be studied; and finally, though not least in importance, the statistician will develop the actual tools of analysis.

Let us assume that the general problem of the administrator is to discover the probable effects, in terms of the nutritional well-being of the population, both as a whole and in terms of various subdivisions, of different economic and social policies which affect the final prices of foods and the net disposable incomes of consumers. The nutritionist has decided how to appraise the consumption figures, at least for individuals of given physical description and activity. We can now consider the economist's approach in more detail.

\section{Food consumption and income}

The economist considers households as economic units which decide how to dispose their incomes in the purchase of foods and other commodities by reference on the one hand to their needs and preferences and on the other to the prices at which the commodities are available. At any moment of time the prices can be assumed constant for all the households; so that the primary economic influence governing variations in a sample of budgets is the variation in the households' incomes. The relation between income and consumption at constant prices is thus the first problem to consider. A summary measure of this relation which is often used by economists is that known as the 'income elasticity of demand', which is approximately equal to the percentage increase in the consumption of a commodity associated with a unit percentage increase in income*. A commodity with an elasticity greater than unity is conventionally known as a 'luxury'; with an elasticity between zero and unity as a 'necessity' (zero denoting a commodity consumed at a constant rate at all levels of income); and a negative elasticity denotes an 'inferior good', since consumption falls as income rises.

In Table I I have given estimates of the income elasticities for a number of foods, the elasticities being measured near the mean incomes of the population; those relating to $1937-8$ are taken from Stone (1954) and are based on an analysis of the Ministry of Labour and Massey surveys carried out at that time; the postwar figures are based partly on my own calculations and partly on those of $\mathrm{Mr} \mathrm{W}$. L. * More strictly the measure is defined $\eta=\frac{\delta \log q}{\delta \log y}=\frac{\delta q}{\delta y} \cdot \frac{y}{q}$, where $q$ is the value of consumption
and $y$ of income. 
Table I. Income elasticities* of the demand for foods in Great Britain. Those for 1937-8 are based on estimates of Stone (1954) and those for 1952-3 on original unpublished material collected in the National Food Survey

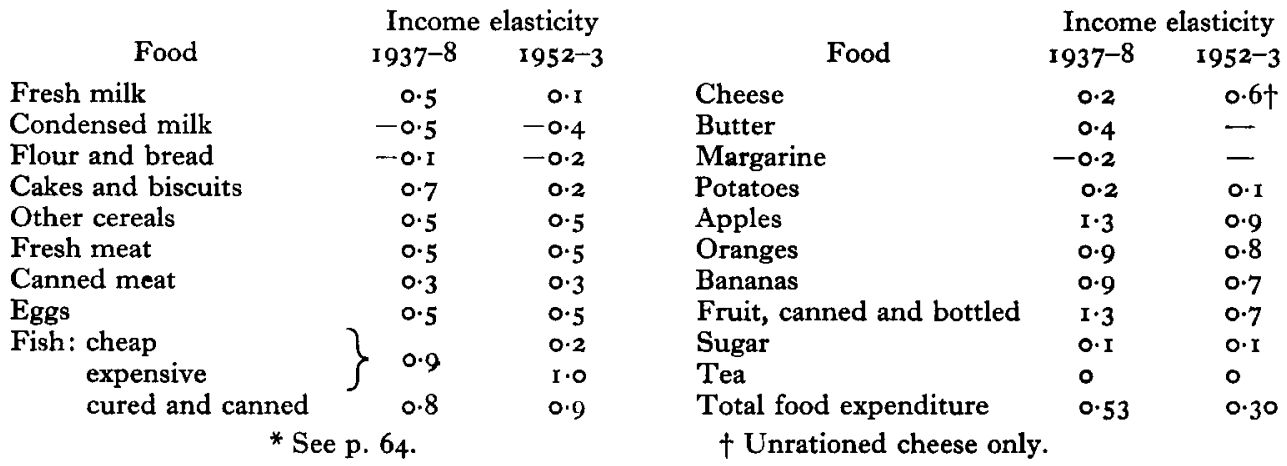

Readman of the Ministry of Food, and the original data are those of the Food Survey.

Table I shows that flour and bread are regarded by households as inferior goods; meat, eggs and butter are moderately income-elastic, whereas fruit was regarded as a luxury before the war and even now is among the most 'expensive' foods. The figures also reveal a fair degree of stability considering the social changes that intervene between the periods and the persistence of rationing in 1952-3. Perhaps the most important difference is the change in the figure for fresh milk which is undoubtedly attributable, in the main, to the welfare policies of the Ministry of Food, though in part it is influenced by the continued shortage of other foods.

Once we admit that these summary measures are useful for a rough ranking of foods according to the extent to which they are regarded by the average household as necessities, we must also admit that for many purposes an explicit mathematical relationship between income and consumption would be much more useful. With the aid of such a relationship (which may be applied to nutritional as well as physical measures of consumption) it is possible to tabulate the values of consumption corresponding to different income levels for the purposes of comparison with nutritional standards. Data and discussion on this relationship are to be found, for this country, in the works of Allen \& Bowley (1935), Orr (1936), Crawford \& Broadley (1938), Nicholson (1949), Houthakker (1952), Prais (1953a) and that of Stone (r954) already cited.

The particular form of the relationship which I myself have found of great use* in the analysis of National Food Survey data is given by

$$
\begin{aligned}
& \mathrm{q}=\kappa \int_{\circ}^{a \mathrm{y}} \frac{\mathrm{I}}{\mathrm{t} \sqrt{2 \pi}} \exp \left[\frac{-(\log \mathrm{t})^{2}}{2}\right] \mathrm{dt} \\
& =\kappa A(\alpha \mathrm{y}),
\end{aligned}
$$

- This equation, and its application to the 1937-8 Ministry of Labour Survey, are discussed by Aitchison \& Brown (1954-5). 
in which $\mathrm{q}$ is the consumption of (or expenditure on) the commodity in question, $\mathrm{y}$ is the net disposable income of the household and $a$ and $\kappa$ are coefficients whose numerical values depend on the commodity. The expression $\Lambda$ (ay) is a convenient way of writing the integral in (I) in which the variables are $a$ and $y$ only; the value of this integral increases from $O$ to $I$ as $y$ increases from $o$ to infinity, so that $q$ correspondingly increases from $\circ$ to $\kappa$. The coefficient $\kappa$ is therefore a measure of the 'saturation level' of consumption which is never exceeded however high the income, whereas $a$ is a measure of the cheapness of the commodity, or alternatively of the urgency with which the commodity is required by the household, since it controls the value of the income elasticity at a given income y. A graph of the general form of the relationship (with a logarithmic scale for income to bring out the characteristic double curvature) is given in Fig. I on which values of the income elasticity are shown; and, referring forward, Fig. 2 depicts the shape of the actual graphs for four different types of household.

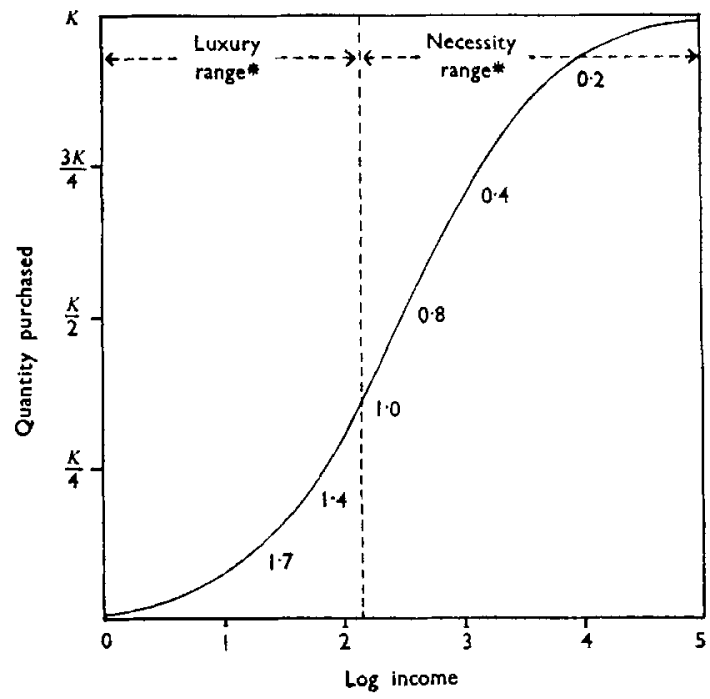

Fig. I. The relation of consumption to income. $\kappa$ is the saturation level of consumption. The figures marked against the curve are the values of the income elasticity of demand.

* See p. 64 .

\section{Food consumption and family composition}

The second problem of the economist is to elaborate the basic model represented by (2) to allow for the effects on food consumption of the composition of the individual household. This is important for several reasons: first, these effects are large; secondly, many social policies such as taxation, family allowances, and rationing, impinge on food consumption by way of the household's composition; and thirdly, the nutritionist is, I think, ultimately interested in anything he can learn from family budgets about the well-being of individual persons, of however indirect a nature.

The problem has often in the past been approached by the well-known device of equivalent-adult scales, or equivalent man-values. These scales have often been 
obtained from compounds of the calorific and nutritional requirements tables (e.g. the 'Amsterdam' scale), or from assessments of the 'cost' of feeding a person of given age and sex (e.g. George, 1937). The crudity of these devices has been pointed out by several workers, of whom the pioneers were Sydenstricker \& King (1921). The most important criticisms are: first that if such scales are useful they must in principle differ for each commodity and again for income, or 'all commodities'; and second, that there is little justification for imposing scales based on a priori considerations of nutrition or cost. Similar criticism can be levelled against the construction of 'minimum-needs' diets for different types of household; observed diets are very different in character and cost from any diet that can genuinely be considered a 'minimum-need' diet; and some calculations I have recently made (Brown, 1954a) show that the results vary considerably if attempts are made to relax the diet in the direction of palatability. Recently, however, the essential concept of equivalent-adult scale has been placed on a basis much more acceptable to economists by the work of Henderson ( $1949 a, b$, I950), Nicholson (1949), Kemsley (1952) and Prais (1953b), following the lines suggested by Sydenstricker \& King (192I). The approach of these workers can be summarized by the model

$$
\frac{\mathrm{q}_{\mathrm{i}}}{\Sigma_{\mathrm{j}} \beta_{\mathrm{ij}} \mathrm{n}_{\mathrm{j}}}=f_{\mathrm{i}} \quad\left(\frac{\mathrm{y}}{\Sigma_{\mathrm{j}} \alpha_{\mathrm{j}} \mathrm{n}_{\mathrm{j}}}\right)
$$

in which the subscript $i$ stands for the commodity, $n_{j}$ for the number of persons of the $j$ 'th type in the household, $f_{\mathrm{i}}$ for the functional relationship between income and consumption, and the coefficients $\beta_{\mathrm{ij}}$ for the equivalent-adult scale specific to the commodity and $\alpha_{\mathrm{j}}$ for the scale appropriate to income. The $\beta_{\mathrm{ij}}$ and $\alpha_{\mathrm{f}}$ are then estimated from the observed budget data. Some results using a model of this type are presented later, but for the moment I would like to present a slightly different approach. An important assumption in model (3) is that the measures of 'size' of the family, $\Sigma_{\mathrm{j}} \beta_{\mathrm{ij}} \mathrm{n}_{\mathrm{j}}$ and $\Sigma_{\mathrm{j}} a_{\mathrm{j}} \mathrm{n}_{\mathrm{j}}$, can be obtained as weighted sums of the number of each type of family member. It seems better to drop this assumption and replace the concept of 'equivalent-adults' with a more general concept of 'equivalent-standardhouseholds'. In terms of our equation (2) we introduce two multipliers $\gamma_{\mathrm{ir}}$ and $\Gamma_{\mathrm{r}}^{-1}$ :

$$
\mathrm{q}_{\mathrm{ir}}=\kappa_{\mathrm{i}} \gamma_{\mathrm{ir}} \Lambda\left(a_{\mathrm{i}} \mathrm{y}_{\mathrm{r}} \Gamma_{\mathrm{r}}^{-1}\right)
$$

the first multiplier, $\gamma_{\mathrm{ir}}$, indicates the ratio of the saturation level of consumption in the r'th type of household (say a household with a married couple and two children) to that of a standard household (say with a married couple only), and the second, $\Gamma_{\mathrm{r}}^{-1}$, which is a weighted average of the reciprocals of the different $\gamma_{\mathrm{ir}}$, serves to correct the money income of the household to its equivalent (in terms of its ability to satisfy relative needs) for the standard household. The coefficients $\gamma_{\mathrm{ir}}$ and $\Gamma_{\mathrm{r}}$ may be measured directly by estimating the coefficients $\kappa$ and $a$ in (2) for different types of household. The coefficients will, of course, be functionally related to the composition of the household; but there is no need to commit ourselves in advance to the linear function implied by (3). In Table 2 I have given 
Table 2. Estimates of the size of households in terms of (a) total food expenditures and $(b)$ the general standard of living $195 \mathrm{I}-2$, based on original unpublished material collected in the National Food Survey

\begin{tabular}{|c|c|c|c|c|c|c|}
\hline \multirow{3}{*}{ Description of household } & \multirow{2}{*}{\multicolumn{3}{|c|}{$\begin{array}{l}\text { Average numbers of } \\
\text { non-adults }\end{array}$}} & \multirow{3}{*}{$\begin{array}{l}\text { Number of } \\
\text { persons }\end{array}$} & \multicolumn{2}{|c|}{$\begin{array}{l}\text { Equivalent household size } \\
\text { in terms of }\end{array}$} \\
\hline & & & & & Food & Standard of \\
\hline & Years & Years & $\begin{array}{l}\text { Years } \\
14-20\end{array}$ & & expenditure & living \\
\hline A married couple* $(2 \mathrm{I}-54$ years $)$ & & & & & & \\
\hline with: no other & - & 一 & - & $2 \cdot 0$ & 2.00 & 2.00 \\
\hline one infant & $I \cdot O$ & - & - & $3 \cdot 0$ & $2 \cdot 34$ & $2 \cdot 46$ \\
\hline two or more infants & $2 \cdot 2$ & - & - & $4 \cdot 2$ & $2 \cdot 58$ & $2 \cdot 9 x$ \\
\hline $\begin{array}{l}\text { one child } \\
\text { one child, one or more in- }\end{array}$ & - & $1 \cdot 0$ & 一 & $3 \cdot 0$ & $2 \cdot 70$ & $3 \cdot 12$ \\
\hline fants & $I \cdot 2$ & $I \cdot 0$ & 一 & $4 \cdot 2$ & $2 \cdot 93$ & $3 \cdot 2 I$ \\
\hline $\begin{array}{l}\text { two or more children } \\
\text { two or more children, one }\end{array}$ & - & $2 \cdot 2$ & 一 & $4 \cdot 2$ & $3 \cdot 27$ & $3 \cdot 44$ \\
\hline or more infants & $I \cdot 4$ & $2 \cdot 2$ & - & $5 \cdot 7$ & $3 \cdot 63$ & $3 \cdot 80$ \\
\hline $\begin{array}{l}\text { one adolescent } \\
\text { one adolescent with child- }\end{array}$ & - & - & $\mathbf{I} \cdot \mathbf{0}$ & $3 \cdot 0$ & $2 \cdot 91$ & $2 \cdot 74$ \\
\hline $\begin{array}{l}\text { ren and infants } \\
\text { two or more adolescents } \\
\text { with children and in- }\end{array}$ & 0.5 & $\mathrm{I} \cdot 4$ & $1 \cdot 0$ & $4 \cdot 8$ & 3.57 & $4 \cdot 00$ \\
\hline $\begin{array}{l}\text { fants } \\
\text { A married couple }(55 \text { years or }\end{array}$ & 0.3 & $1 \cdot 0$ & $2 \cdot 2$ & $5 \cdot 5$ & 4.02 & $4 \cdot 25$ \\
\hline more) & - & - & - & 2.0 & $\mathrm{I} \cdot 18$ & I 49 \\
\hline
\end{tabular}

estimates of the coefficients $\gamma_{\mathrm{ir}}$ and $\Gamma_{\mathrm{r}}$ for common types of household in which Food Survey data for total domestic food expenditure in $195^{\mathrm{L}}$ and $195^{2}$ have been used, after making the necessary correction for different levels of prices and incomes prevailing in the two years. And in Fig. 2 I have shown the graphs (derived from these estimates) for four types of household to illustrate their implications.

The estimates of Table 2 are not as firm as could be wished for purposes of policy, but the estimates of the saturation expenditure ratios $\left(\gamma_{\mathrm{ir}}\right)$ do cast some doubt on the appropriateness of a straightforward, linear scale of equivalent adults for food expenditure, since the estimates are smaller, in the larger households, than such a

Table 3. Equivalent-adult scales calculated for total food expenditure and certain nutritional measures of the domestic diet, estimated from earlier calculations of Brown (1954b)

\begin{tabular}{lccccc} 
& \multicolumn{2}{c}{ Parbo- } & \multicolumn{2}{c}{ Protein } & \\
& Food expenditure & hydrate & Vegetable & Animal & Vitamin C \\
First couple in the household & 2.00 & 2.00 & 2.00 & 2.00 & 2.00 \\
Other male adult & 0.90 & 1.28 & 1.36 & 0.98 & 0.70 \\
Other female adult & 0.87 & 0.73 & 0.71 & 0.79 & 0.84 \\
Adolescent I4-20 years & 1.01 & 1.28 & 1.36 & 0.82 & 1.08 \\
Child 4-13 years & 0.68 & 0.74 & 0.70 & 0.65 & 0.71 \\
Infant 0-4 years & 0.59 & 0.61 & 0.47 & 0.75 & 0.65 \\
Income elasticities & 0.30 & 0 & 0 & 0.18 & 0.30
\end{tabular}

* Aged 21 or more years. 


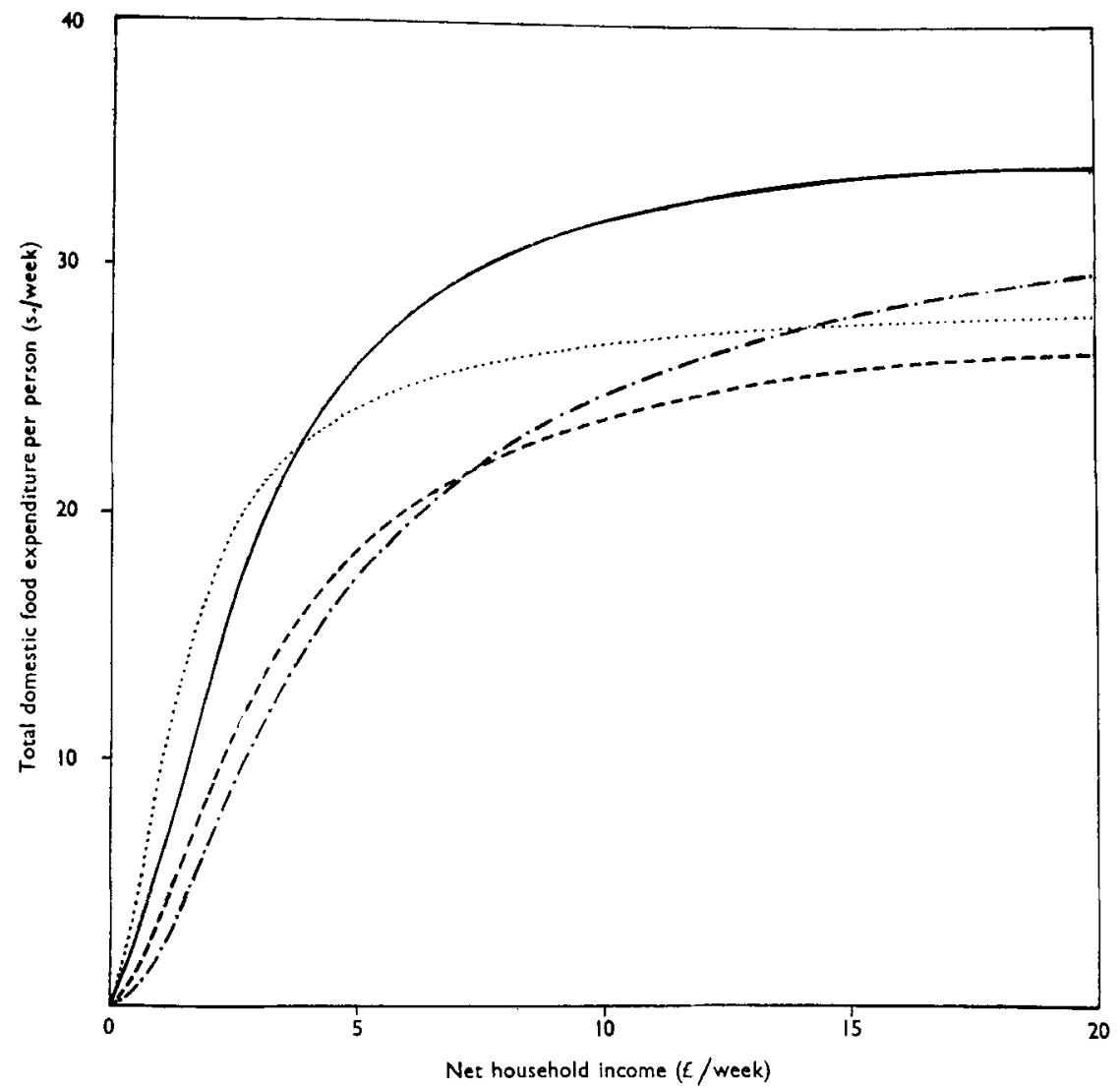

Fig. 2. Total food expenditure and income in four types of household (at prices and incomes of the second half of 1952), - - married couple aged $2 \mathrm{I}-54$ years; $--\longrightarrow$, same couple with one infant aged $0-4$ years ; _ _.. - , same couple with one child aged $5-14$ years; . . . , married couple aged 55 years or more.

scale would suggest. For many purposes, however, (rationing for example), administrative action must be taken as though the scale were linear, and in Table 3 I have given some estimates from earlier calculations (Brown, 1954b) made on this assumption.

\section{Use of economic concepts}

We may now briefly consider the use of such calculations to the nutritionist and administrator. First, the estimation of the parameters $\kappa_{i}, a_{i}, \gamma_{1 \mathbf{r}}$ and $\Gamma_{\mathrm{r}}$ for different foods and different types of household allows us to calculate the income levels for the different households at which their members may be considered nutritionally vulnerable, in the sense that their diets are inadequate according to some objective standards. Secondly a knowledge of the parameters allows us to estimate the effects of different social policies: if families are far from achieving their saturation expenditures, policies affecting their disposable incomes will lead 
to a relatively large improvement in their diets; otherwise, such improvements can only be gained by policies that raise the family's subjective estimates of its requirements, which are reflected in the saturation coefficients $\kappa_{i}$. In particular the values of $\gamma_{\text {ir }}$ may suggest that certain types of household (say those containing young children) underestimate their needs of some foods which may be the main source of a particular nutrient. Before any administrative action is taken a more detailed inquiry may be necessary in which more extensive and more accurate measurements are made; but the final action may take the form of using other foods as a vehicle for the nutrient, or of direct attempts to improve the nutrition of particular age groups, or of general educational measures, and so on.

Thirdly, the computational model may be used in further analysis, in order to compare the values of the parameters obtained for different countries or for different social and occupational groups in the same country. A great deal of work of this nature has already been done in terms of simple averages; for example we have the type of figures given in the reports of the National Food Survey Committee (see, e.g., Ministry of Food: National Food Survey Committee, I953). A greater depth can be given to this type of analysis, however, by using the concepts of average relationships between food consumption, income and household composition, in addition to the straightforward averages to which we are now accustomed.

I am glad to acknowledge the full access given to National Food Survey data by the Ministry of Food; and the help of a number of friends, including Richard Stone, Director of the Department of Applied Economics, John Aitchison, also of the Department, and my former colleagues of the Ministry of Food, in particular W. L. Kendall who first encouraged me to study the problems discussed.

\section{REFERENCES}

Aitchison, J. \& Brown, J. A. C. (1954-5). Rev. econ. Stud. 22, 35.

Allen, R. G. D. \& Bowley, A. L. (1935). Family Expenditure. London: Staples.

Brown, J. A. C. (r954a). Paper read to the Ferranti Conference on Linear Programming: to be published in the Conference Proceedings.

Brown, J. A. C. (1954b). Econometrica, 22, 4.

Crawford, W. \& Broadley, H. (1938). The People's Food, London: William Heinemann Ltd.

George, R. F. (1937). F. R. statist. Soc. 100, 74.

Henderson, A. M. (1949a). Rev. econ. Stud. 17, 127.

Henderson, A. M. (1949b). Popul. Stud. 3, 130.

Henderson, A. M. (1950). Popul. Stud. 4, 267.

Houthakker, H. S. (1952). F. R. statist. Soc. A, I15, I.

Kemsley, W. F. F. (1952). Appl. Statist. 1, 192.

Ministry of Food: National Food Survey Committee (1953). Domestic Food Consumption and Expenditure, I95I. London: H.M. Stationery Office.

Nicholson, J. L. (1949). F. R. statist. Soc. 112, 359 .

Orr, J. B. (1936). Food, Health and Income, London: Macmillan \& Co. Ltd.

Prais, S. J. (1953a). Rev. econ. Stud. 20,87.

Prais, S. J. (I953b). Econ. 7. 63, 791.

Stone, J. R. N. (1954). The Measurement of Consumers' Expenditure and Behaviour in the United Kingdom 1920-38, Vol. I. Cambridge: University Press.

Sydenstricker, E. \& King, W. I. (I92 I). Quart. Publ. Amer. statist. Ass. 17, 842. 